\title{
CERVICO-MANDIBULAR \\ MUSCLE ACTIVITY IN FEMALES WITH CHRONIC CERVICAL PAIN
}

\begin{abstract}
Pathophysiological mechanisms behind pain in chronic cervical musculoskeletal conditions (MSC) in office workers remain unclear. Chronic cervical pain has established links with temporomandibular (TM) disorders. Yet there is no current published evidence to report whether individuals with cervical dysfunction exhibit altered masseter and cervical extensor (CE) muscle activity. Objective: To explore CE and masseter surface electromyographic (sEMG) activity and teeth clenching habits in females with chronic cervical dysfunction and no TM disorder. Design: Descriptive cross-sectional correlational study with singleblinding. Participants: University students and staff with or without chronic cervical pain and no TM involvement. Methods: Descriptive and pain data captured from Research Diagnostic Criteria for TM disorders, Neck

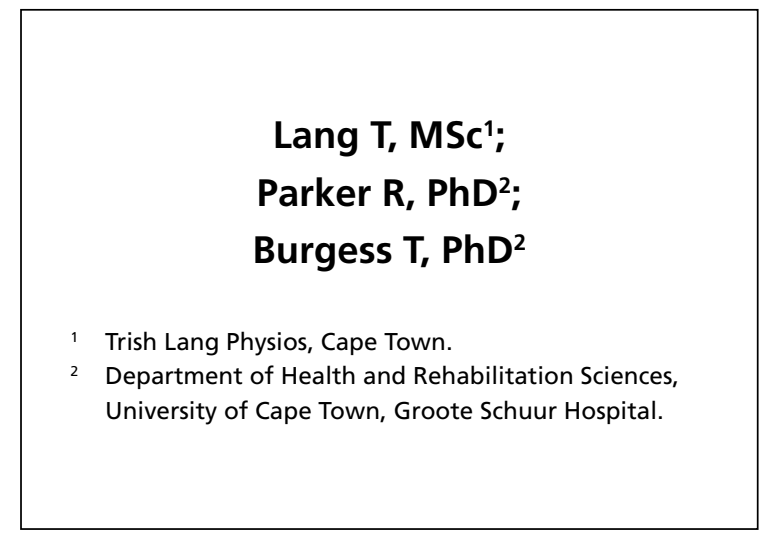
Disability Index, Computer Usage, Brief Pain Inventory, and EuroQoL-5D questionnaires. Female participants allocated to a chronic cervical $(n=20)$ and a control group $(n=22)$. Investigator blinded to the study groups recorded SEMG of bilateral masseter and CE muscles (C4/5 level) at rest and during light teeth clenching. Results: No differences in socio-demographic profile; or in masseter or CE SEMG activity at rest or during light clench between groups. The pain group had higher scores for pain, reported a daytime teeth clenching habit, and had worse scores for the healthrelated quality of life (HRQoL) sub-sections for pain, anxiety/depression, and lower scores for perceived health status. Conclusion: No relationship established between cervico-mandibular sEMG activity and reported disability in females with chronic cervical dysfunction and no TM disorder. Association between biopsychosocial factors of teeth clenching and anxiety/depression highlights complex pathophysiological mechanisms in chronic recurrent cervical pain.
\end{abstract}

KEY WORDS: CHRONIC CERVICAL PAIN, TEMPOROMANDIBULAR, SURFACE ELECTROMYOGRAPHY, TEETH CLENCHING

\section{INTRODUCTION}

Musculoskeletal pain conditions (MSC) of the spine are a burden in both developed and developing countries with the prevalence of cervical pain ranging from $12 \%$ to $80 \%$ (Haldeman et al 2009; Smuts 2008). Those with chronic cervical pain report the presence of pain for at least three to six months in the past year, and may experience at

\section{Correspondence Author:}

Trish Lang

Trish Lang Physios

Room 301, Christiaan Barnard Annexe

162 Longmarket Street

Cape Town 8001

Email: trish.lang@mweb.co.za least four recurrent episodes of cervical pain lasting three or more days in the past year. Chronic cervical MSC is a growing socio-economic burden due to the severity, duration and recurrence of symptoms, particularly among sedentary office workers (Waersted et al 2010).

Individuals with temporomandibular (TM) disorders have a 2.37 times increased risk for cervical pain (Catanzariti et al 2005). Daytime teeth clenching, a component of bruxism, has been identified as a complex predisposing or perpetuating factor for TM disorders (Ciancaglini et al 2001). There may be a potential impact of teeth clenching on the cervical spine in individuals with TM disorders (Catanzariti et al 2005). Further, there may be relationships between the masseter and cervical muscles during teeth clenching in healthy participants (Tecco et al 2007). However, a number of methodological limitations in previous studies, including the absence of screening for isolated TM or cervical disorders, limits the interpretation of these findings (Castroflorio et al 2008). In addition, there is a lack of empirical evidence regarding muscle activity in the masseter and CE muscles and teeth clenching habits in individuals with cervical dysfunction only. Therefore, the aim of the current study was to explore cervico-mandibular muscle activity and reported disability in females with chronic cervical MSC, with no reported symptoms of TM disorders. 


\section{METHODS}

The study had a descriptive crosssectional design with single-blinding. A sample size of 40 participants (two groups of 20) was required. Sample size was calculated using differences in surface electromyographic (sEMG) levels of the $\mathrm{CE}$ in individuals with and without cervical pain (Johnston et al 2008) using a significance level of $\mathrm{p}<0.05$ and a power of 0.9 , with a minimal detectable difference in sEMG activity of the CE of $1.3 \pm 2.5 \mu \mathrm{V}$ between groups.

Female students and staff from the University of Cape Town, with and without chronic cervical MSC, aged between 21 to 45 years were recruited for the study. Recruitment of volunteers through advertisement was followed by a telephonic consent and screening process. The telephonic screening process identified those with and without chronic or chronic recurrent cervical pain and disability, based on specific questions from the Neck Disability Index (NDI) (Vernon and Mior 1991). The screening procedure was also used to exclude volunteers based on specific TM questioning using the adapted Research Diagnostic Criteria for TMD History questionnaire (RDC/ TMD) (Dworkin and LeReche, 1992). Exclusion criteria included the reporting of TM symptoms or a history of fracture, trauma or surgery to the mandibular or cervical area, a history of prosthodontic or orthodontic procedures, or removal of more than one tooth per quadrant (excluding third molars). Participants were also excluded if they were receiving any form of cervical treatment other than Schedule One or Two analgesics at the time of the study, or had general medical disorders such as fibromyalgia, myositis or myalgia. In addition, participants with a BMI greater than 30 $\mathrm{kg} \cdot \mathrm{m}^{-2}$ were excluded, due to the confounding influence of subcutaneous fat on sEMG (Nordander et al 2003). Volunteers who fulfilled these criteria were invited to participate in the study.

All participants who were recruited by the initial telephonic screening process attended Groote Schuur Hospital, Cape Town where written informed consent was obtained. Ethical approval for the study was obtained from the Faculty of Health Sciences Human Research Ethics Committee of the University of Cape Town (HREC REF 316/2010). Participants were allocated a code to maintain blinding and asked to complete five questionnaires: the adapted RDC/ TMD History questionnaire (Dworkin and LeResche 1992), the Neck Disability Index (NDI) (Vernon and Mior 1991), the Computer Usage Questionnaire (CUQ) (Smith et al 2009), the Brief Pain Inventory (BPI) (Cleeland and Ryan 1994), and the EuroQoL-5D (EQ-5D) (Jelsma et al 2004). The RDC/TMD was used as an instrument to confirm exclusion of a TM disorder, and to provide data on the presence or absence of a reported daytime parafunctional teeth clenching habit. The remaining four questionnaires were used to determine levels of cervical disability, as well as levels of occupational and sporting activity, pain-related disability and HRQoL. On completion of the questionnaires, the research assistant assigned participants to the pain or control groups dependent on NDI scores. Participants were allocated to the pain group if they were categorised with "mild disability" to "completely disabled" (5 - 50 points) on the NDI, whereas participants were allocated to the control group if they were categorised with "no disability" ( $0-4$ points $)$ on the NDI. All completed questionnaires were stored in a sealed opaque envelope by the research assistant and opened by the principle investigator (PI) only once the data for the entire study had been collected. The PI was blinded to the groups until all data were collected. The PI was unblinded for data analysis.

The Myotrace 400 sEMG recorder was used to determine muscle activity of the masseter and CE muscles. Participants were seated for testing in an allocated chair, which provided back support to scapular height, without head support. Four disposable $\mathrm{Ag} / \mathrm{AgCl}$ circular electrodes with a $0.8 \mathrm{~cm}$ diameter were applied to the right and left masseter and CE (superficial muscles of the splenius capitis and cervicis) muscles in parallel to the muscle fibre direction (Castroflorio et al 2008).

Electrode placement for the superficial masseter was over the body of the muscle $2 \mathrm{~cm}$ anterior and $1 \mathrm{~cm}$ above the mandibular angle, with an interelectrode distance for the second masseter electrode of $2.5 \mathrm{~cm}$ above the first, measured from centre point to centre point. Electrode placement for the right and left $\mathrm{CE}$ muscles respectively was $1 \mathrm{~cm}$ lateral to the $\mathrm{C} 4$ and $\mathrm{C} 5$ spinous processes, with an inter-electrode distance of $2 \mathrm{~cm}$ above the first (Cram and Kasman 1998). Electrode cable fixation ensured lack of cable movement or tension during the recording. Recording took place over $10 \mathrm{~s}$ periods in two positions: a standardised sitting position at rest, and the position of first posterior tooth contact (the intercuspal position short of a light clench). Quality and maintenance of the position at rest and of "first tooth contact" was achieved during a practice trial and recording periods, under supervision of the PI with the use of the sEMG signal on the Myotrace 400 screen. Maximum voluntary contraction values for each muscle group were performed for normalisation of sEMG data. These were done after the $10 \mathrm{~s}$ recordings, to avoid any influence on resting activity levels. Maximal resisted cervical extension for the superficial CE was performed against an air pressure sensor inflated to $20 \mathrm{~mm} \mathrm{Hg}$, with verbal encouragement for participant feedback.

\section{STATISTICAL ANALYSES}

The Shapiro-Wilk test for normality was conducted to determine the distribution of the data. Data were analysed using the Mann-Whitney U and chi-squared $\left(\chi^{2}\right)$ tests. Spearman correlation tests were performed to determine associations between variables. Secondary analyses were conducted using teeth clenching and anxiety/depression as grouping variables. Statistical significance was accepted as $\mathrm{p}<0.05$.

\section{RESULTS}

Forty-two participants were recruited for the study. Twenty participants formed the pain group and the control group consisted of 22 participants. There were no differences in socio-demographic characteristics (age, BMI, occupation, number of hours spent with computerrelated sitting, or number of hours involved in sports activities) between the pain and control groups (Table 1). 
Table 1: Socio-demographic characteristics $(\mathrm{N}=42)$

\begin{tabular}{|c|c|c|c|c|}
\hline & \multicolumn{2}{|c|}{ Pain group $(n=20)$} & \multicolumn{2}{|c|}{ Control group $(n=22)$} \\
\hline & Mean \pm SD & Frequency (\%) & Mean \pm SD & Frequency (\%) \\
\hline Age (years) & $27.4 \pm 5.2$ & & $28.2 \pm 7.3$ & \\
\hline BMI $\left(\mathrm{kg} \cdot \mathrm{m}^{-2}\right)$ & $23.7 \pm 5.7$ & & $24.9 \pm 4.9$ & \\
\hline \multicolumn{5}{|l|}{ Occupation } \\
\hline Student & & 50 & & 59.1 \\
\hline Staff & & 50 & & 40.9 \\
\hline Sit $\left(h . w k^{-1}\right)$ & $26.1 \pm 13.7$ & & $26.2 \pm 17.5$ & \\
\hline Sport (h.wk $\left.k^{-1}\right)$ & $0.5 \pm 1$ & & $1.5 \pm 2.3$ & \\
\hline
\end{tabular}

Table 2: Surface EMG data of masseter and cervical extensors at rest $(\mathrm{N}=\mathbf{4 2})$

\begin{tabular}{|c|c|c|}
\hline & Pain group $(\mathbf{n}=\mathbf{2 0})$ & Control group $(\mathbf{n}=22)$ \\
\hline Mean sEMG & Mean \pm SD & Mean \pm SD \\
\hline Masseter & & $4.73 \pm 4.64$ \\
\hline Right (0-5 s) & $5.36 \pm 4.69$ & $4.68 \pm 4.69$ \\
\hline Right (6-10 s) & $5.28 \pm 4.66$ & $4.10 \pm 5.25$ \\
\hline Left (0-5 s) & $4.43 \pm 3.71$ & $3.96 \pm 4.70$ \\
\hline Left (6-10 s) & $4.31 \pm 3.65$ & $14.75 \pm 12.65$ \\
\hline Cervical extensors & & $14.77 \pm 12.61$ \\
\hline Right (0-5 s) & $14.85 \pm 7.36$ & $17.12 \pm 17.28$ \\
\hline Right (6-10 s) & $14.90 \pm 7.51$ & $16.99 \pm 17.19$ \\
\hline Left (0-5 s) & $15.43 \pm 6.88$ & \\
\hline Left (6-10 s) & $15.40 \pm 6.83$ & \\
\hline
\end{tabular}

Table 3: Surface EMG data of masseter and cervical extensors during light teeth contact $(\mathrm{N}=\mathbf{4 2})$

\begin{tabular}{|c|c|c|}
\hline & Pain group $(\mathbf{n}=\mathbf{2 0})$ & Control group $(\mathbf{n}=\mathbf{2 2})$ \\
\hline Mean sEMG & Mean \pm SD & Mean \pm SD \\
\hline Masseter & & $5.42 \pm 5.05$ \\
\hline Right (0-5 s) & $5.64 \pm 4.86$ & $5.45 \pm 4.92$ \\
\hline Right (6-10 s) & $5.58 \pm 4.81$ & $4.49 \pm 4.69$ \\
\hline Left (0-5 s) & $4.64 \pm 3.61$ & $4.45 \pm 4.62$ \\
\hline Left (6-10 s) & $4.56 \pm 3.54$ & $15.14 \pm 12.49$ \\
\hline Cervical extensors & & $15.32 \pm 12.58$ \\
\hline Right (0-5 s) & $14.08 \pm 7.00$ & $16.81 \pm 15.57$ \\
\hline Right (6-10 s) & $14.01 \pm 7.00$ & $17.09 \pm 15.65$ \\
\hline Left (0-5 s) & $14.88 \pm 6.02$ & $14.60 \pm 5.83$ \\
\hline Left (6-10 s) & & \\
\hline
\end{tabular}

There were no significant differences between groups in the masseter or $\mathrm{CE}$ muscle activity either at rest or during first posterior tooth contact (Table 2 and Table 3) as well as in the rate of change over time in bilateral masseter or $\mathrm{CE}$ muscle activity during the $10 \mathrm{~s}$ of first posterior tooth contact.

The pain group reported significantly higher levels of disability $(\mathrm{U}=0$; $\mathrm{p}<0.01)$, pain $(\mathrm{U}=50 ; \mathrm{p}<0.01)$, and a greater presence of daytime teeth clenching $\left(\chi^{2}=6.48 ; \mathrm{p}<0.01\right)$ (Table 4).

The pain group also had significantly worse scores for the HRQoL subsections of pain $\left(\chi^{2}=24.44 ; \mathrm{p}<0.01\right)$, and anxiety/depression $\left(\chi^{2}=7.82 ; \mathrm{p}<0.05\right)$, with a lower overall perceived health status $(\mathrm{U}=129.50 ; \mathrm{p}<0.02)$ (Figure 1).

There were significant positive relationships between cervical disability and pain for the total sample $\left(\mathrm{r}_{\mathrm{s}}=0.80\right.$; $\mathrm{p}<0.05)$, the pain group $\left(\mathrm{r}_{\mathrm{s}}=0.72 ; \mathrm{p}<\right.$ $0.05)$, and the control group $\left(r_{\mathrm{s}}=0.50\right.$; $\mathrm{p}<0.05)$. There were significant inverse relationships between cervical disability and state of health for the total sample $\left(r_{s}=-0.35 ; p<0.05\right)$ indicating that as cervical disability increased, state of health decreased. However, there were no significant relationships between cervical disability and state of health when groups were analysed separately.

Factors found to be significantly different between the experimental and control groups were used as grouping variables in a secondary analysis (Table 5 and Table 6). Firstly, the variable of daytime teeth clenching was used as a grouping variable to explore for differences in NDI, pain, HRQoL, and sEMG. Secondary analysis showed that participants who reported teeth clenching also reported higher levels 
of cervical disability $(\mathrm{U}=-104.50$; $\mathrm{p}<0.02)$, higher levels of pain and discomfort on the EQ-5D index $\left(\chi^{2}=\right.$ 5.46; $\mathrm{p}<0.02)$, and higher levels of anxiety/depression $\left(\chi^{2}=6.84 ; p<0.01\right)$, compared to participants who did not report teeth clenching (Table 5). No relationships were observed between the presence of teeth clenching and resting sEMG activity levels in the masseter and CE muscles respectively.

Similarly, HRQoL was also used as a sub-group analysis variable to explore differences in NDI, pain, presence of teeth clenching, and sEMG. Secondary analysis showed that participants who reported experiencing anxiety/ depression on the HRQoL instrument reported higher levels of cervical disability $(U=58.00 ; p<0.01)$, higher levels of pain and discomfort on the EQ-5D index $(\mathrm{U}=54.00 ; \mathrm{p}<0.01)$, a lower perceived state of health $(U=62.00 ; p<0.01)$, and a higher prevalence of teeth clenching habits $\left(\chi^{2}=6.84 ; p<0.01\right)$ compared to participants who did not report anxiety/ depression (Table 6). However, no significant relationships were observed between anxiety/depression and resting sEMG activity levels in the masseter and CE muscles respectively.

\section{DISCUSSION}

Literature suggests that changes in resting sEMG levels and firing patterns may indicate potential underlying structural involvement associated with chronic cervical pain (De Sade 2011; Madeleine 2010). However, in this study there were no significant relationships between changes in sEMG activity levels and chronic cervical MSC. In this study, the absence of changes in resting CE sEMG activity in the pain group concurs with the results of a previous study of individuals with chronic MSC of the cervical-shoulder region (Madeleine 2010). In contrast, Johnston et al (2008) showed an increase in resting sEMG $\mathrm{CE}$ activity in the presence of cervical pain-related disability. Tecco et al (2007) demonstrated the relationship between the masseter and CE muscles during experimental teeth clenching. It is possible that the differences may be due to differences in inclusion criteria. In the present study, participants included females with and without chronic cervical pain; whereas Tecco et al (2007) investigated changes in pain free participants only. In addition, many investigations did not normalise sEMG

data (Tecco et al 2007; Svensson et al 2004). These differences may potentially account for the dissimilar findings in current literature.

Table 4: Cervical disability (NDI), pain (BPI) and prevalence of teeth clenching $(\mathrm{N}=42)$

\begin{tabular}{|c|c|c|}
\hline & Pain group $(n=20)$ & Control group $(n=22)$ \\
\hline & Mean \pm SD & Mean \pm SD \\
\hline NDI & $11.00 \pm 4.72 *$ & $2.00 \pm 1.20 *$ \\
\hline BPI & $3.84 \pm 1.54 *$ & $1.11 \pm 1.61 *$ \\
\hline Daytime teeth clench & Frequency (\%) & Frequency (\%) \\
\hline $\begin{array}{l}\text { Not reporting } \\
\text { daytime teeth } \\
\text { clenching }\end{array}$ & $50 *$ & $86.4^{*}$ \\
\hline $\begin{array}{l}\text { Reporting daytime } \\
\text { teeth clenching }\end{array}$ & $50 *$ & $13.6 *$ \\
\hline
\end{tabular}

Table 5: Daytime teeth clenching as a grouping variable $(\mathbf{N}=\mathbf{4 2})$

\begin{tabular}{|c|c|c|c|c|}
\hline \multirow[t]{2}{*}{ Instruments } & \multicolumn{2}{|c|}{$\begin{array}{l}\text { No Teeth Clenching } \\
\qquad N=29\end{array}$} & \multicolumn{2}{|c|}{$\begin{array}{l}\text { Teeth Clenching } \\
\qquad N=13\end{array}$} \\
\hline & Mean \pm SD & $\begin{array}{c}\text { Frequency } \\
(\%)\end{array}$ & Mean \pm SD & $\begin{array}{l}\text { Frequency } \\
\text { (\%) }\end{array}$ \\
\hline Cervical Disability (NDI) & $5.3 \pm 5.6^{*}$ & & $8.5 \pm 5.3^{*}$ & \\
\hline Pain & $2.2 \pm 2.1$ & & $2.9 \pm 2.1$ & \\
\hline \multicolumn{5}{|l|}{ HRQoL } \\
\hline State of health VAS & $7.6 \pm 1.9$ & & $6.9 \pm 1.9$ & \\
\hline No pain/discomfort & & $62.1 *$ & & $23.1 *$ \\
\hline $\begin{array}{l}\text { Not anxious or } \\
\text { depressed }\end{array}$ & & $89.7 *$ & & $53.8 *$ \\
\hline
\end{tabular}

Table 6: Anxiety/depression as a grouping variable $(\mathrm{N}=42)$

\begin{tabular}{|c|c|c|c|c|}
\hline \multirow[t]{2}{*}{ Instruments } & \multicolumn{2}{|c|}{$\begin{array}{c}\text { Anxiety No } \\
N=33\end{array}$} & \multicolumn{2}{|c|}{$\begin{array}{c}\text { Anxiety Yes } \\
\qquad N=9\end{array}$} \\
\hline & Mean \pm SD & Frequency & Mean \pm SD & Frequency \\
\hline $\begin{array}{l}\text { Cervical Disability } \\
\text { (NDI) }\end{array}$ & $\begin{array}{l}5.06 \pm \\
5.02 *\end{array}$ & & $\begin{array}{c}10.78 \pm \\
5.74^{*}\end{array}$ & \\
\hline Pain & $\begin{array}{l}1.92 \pm \\
1.95^{\star}\end{array}$ & & $\begin{array}{c}4.22 \pm \\
1.50 *\end{array}$ & \\
\hline \multicolumn{5}{|l|}{ HRQoL } \\
\hline $\begin{array}{l}\text { State of health } \\
\text { VAS }\end{array}$ & $\begin{array}{l}7.82 \pm \\
1.46^{*}\end{array}$ & & $\begin{array}{l}5.59 \pm \\
2.40 *\end{array}$ & \\
\hline $\begin{array}{l}\text { Reporting daytime } \\
\text { teeth clenching }\end{array}$ & & $21.21 *$ & & $66.7 *$ \\
\hline
\end{tabular}



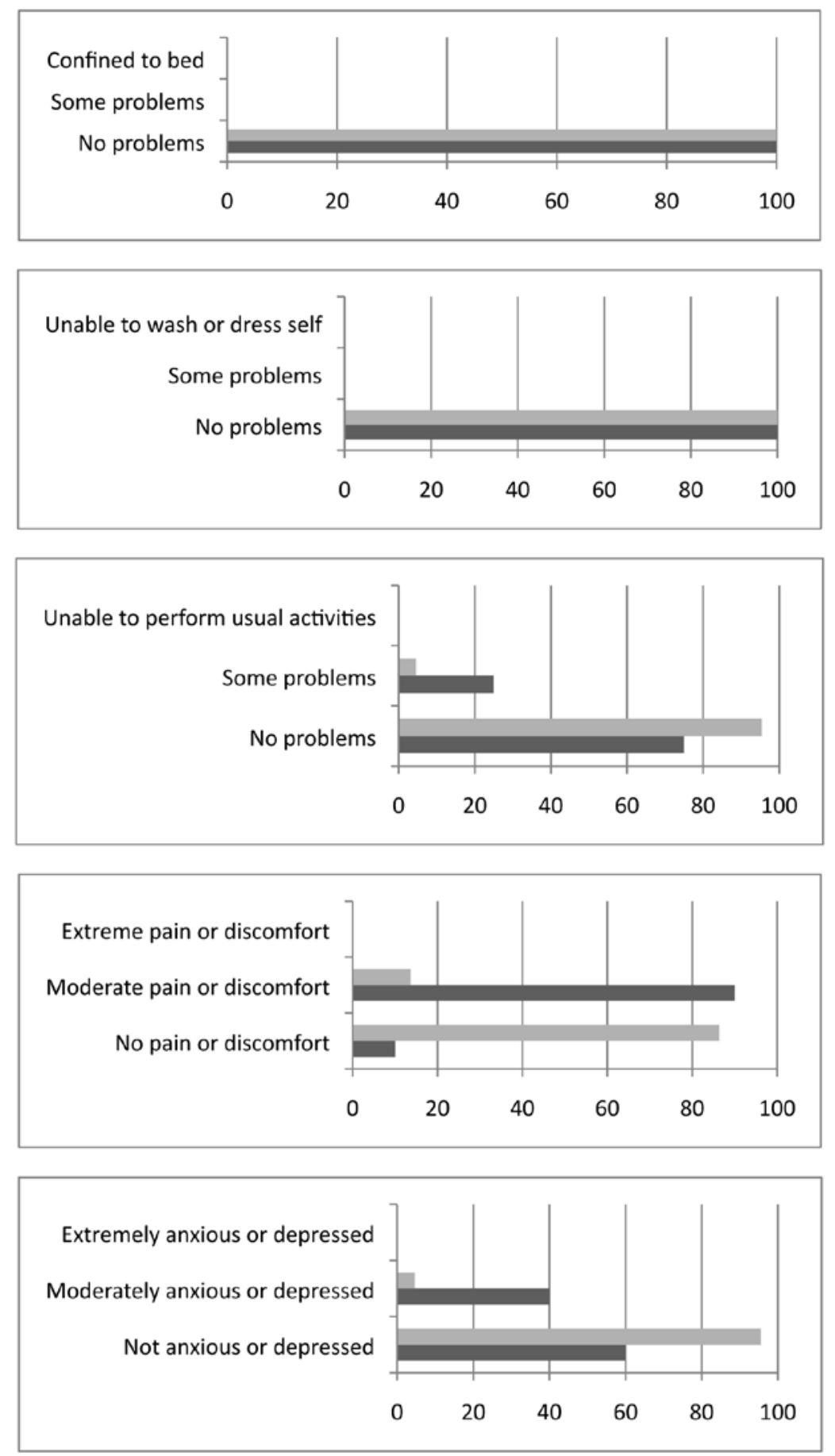

Pain group in dark grey and control group in light grey

Figure 1: Health related quality of life as measured on the EQ-5D $(N=42)$

The relationships between cervical disability, the presence of teeth clenching, and anxiety/depression that were observed in this study may indicate the presence of pathophysiological mechanisms associated with chronic recurrent cervical pain, which extend beyond the peripheral nociceptive system (Catanzariti et al 2005). These interrelationships support the biopsychosocial model of pain, and contribute to the literature identifying the multiple factors that may contribute to chronic cervical pain through central sensitisation and central nervous system changes (Moseley 2003).

In chronic pain, both the peripheral nociceptive and the central non-nociceptive systems generate and undergo physiological changes. This may lead to long-term alterations in the central nervous system, and further changes in pain and motor control output in the cortical pain neuromatrix (Loeser and Melzack 1999). In addition, the brain is able to generate or augment pain in the absence of nociceptive input from the periphery or spinal cord (Loeser and Melzack 1999). In the present study, somatic (peripheral nociceptive) input mechanisms for cervical pain were not excluded. However, no significant sEMG changes in the $\mathrm{CE}$ and masseter muscles were recorded suggesting no or minimal activation of the peripheral nociceptive system by these muscles. It is possible that the central non-nociceptive factors of cervical disability, teeth clenching habits and anxiety/depression may be contributing to the presence of chronic cervical pain.

Possible limitations of this study are related to the sEMG methodology. Despite careful placement of electrodes, possible cross talk between the superficial erector spinae and the trapezius muscles may have influenced sEMG recordings (Castroflorio et al 2008). In addition, the use of short duration time measures (10 seconds) for the recording of sEMG may also have minimised any differences in sEMG activity between the pain and control groups (De Sade 2011). In future studies, longer recording durations of approximately two minutes of sEMG activity are recommended (De Sade 2011).

\section{CONCLUSION}

This study found no relationship between cervico-mandibular muscle activity and reported disability in females with chronic cervical dysfunction and no TM disorder. However, the association of the biopsychosocial factors of teeth clenching behaviours and anxiety/ depression highlights the complex pathophysiological mechanisms found in chronic recurrent cervical pain. These findings reinforce the need for biopsychosocial assessment and management strategies in these patient groups. It is recommended that clinicians perform a comprehensive assessment of patients with chronic recurrent cervical pain incorporating the multifactorial nature of this condition. Clinicians should specifically consider the severity 
of cervical disability, the possible role of daytime teeth clenching behaviour, and the role of anxiety/depression in the assessment and management of chronic cervical pain.

\section{REFERENCES}

Castroflorio T, Bracco P, Farina D 2008 Surface electromyography in the assessment of jaw elevator muscles. Journal of Oral Rehabilitation 35(8):638-645

Catanzariti JF, Debuse T, Duquesnoy B 2005 Chronic neck pain and masticatory dysfunction. Joint, Bone, Spine: Revue du Rhumatisme 72(6):515-519

Ciancaglini R, Gherlone EF, Radaelli G 2001 The relationship of bruxism with craniofacial pain and symptoms from the masticatory system in the adult population. Journal of Oral Rehabilitation 28(9):842-848

Cleeland CS, Ryan KM 1994 Pain assessment: global use of the Brief Pain Inventory. Annals of the Academy of Medicine, Singapore 23(2): 129-138

Cram JR, Kasman GS 1998 Electrode placements. In: Cram JR, Kasman GS (ed) Introduction to Surface Electromyography, pp252-270. Aspen Publishers, Gaithersburg

De Sade M 2011 Psychophysiological assessment of chronic pain. In: Flor HT, Turk DC (ed) Chronic Pain: An Integrated Biobehavioural approach, pp198-216. International Association for the Study of Pain, Seattle

Dworkin SF, LeResche L 1992 Research diagnostic criteria for TM disorders: review, criteria, examinations and specifications, critique. Journal of Craniomandibular Disorders : facial \& oral pain 6(4):301-355

Haldeman S, Carroll L, Cassidy JD, Schubert J, Nygren A 2009 The Bone and Joint Decade 2000-2010 Task Force on Neck Pain and Its Associated Disorders: executive summary. Journal of Manipulative and Physiological Therapeutics 32(2):S7-S9

Jelsma J, Mkoka S, Amosun, L, Nieuwveldt J 2004 The reliability and validity of the Xhosa version of the EQ-5D. Disability and Rehabilitation 26(2):103-108
Johnston V, Jull G, Souvlis, T, Jimmieson NL 2008 Neck movement and muscle activity characteristics in female office workers with neck pain. Spine 33(5):555-563

Loeser JD, Melzack R 1999 Pain: an overview. Lancet 353(9164):1607-1609

Madeleine P 2010 On functional motor adaptations: from the quantification of motor strategies to the prevention of musculoskeletal disorders in the neck-shoulder region. Acta Physiologica 199(679):S1-S46

Moseley GL 2003 A pain neuromatrix approach to patients with chronic pain. Manual Therapy $8(3): 130-140$

Nordander C, Willner J, Hansson GA, Larsson B, Unge J, Granquist L 2003 Influence of the subcutaneous fat layer, as measured by ultrasound, skinfold calipers and BMI, on the EMG amplitude. European Journal of Applied Physiology 89(6):514-519

Smith L, Louw Q, Crous L, Grimmer-Somers K 2009 Prevalence of neck pain and headaches: impact of computer use and other associative factors. Cephalalgia: An International Journal of Headache 29(2):250-257

Smuts M 2008 Mental health and chronic pain conditions in a nationally-representative sample of South African adults: a cross-sectional study. MPH (Public Health) University of Cape Town Unpublished thesis

Svensson P, Wang, K, Sessle, BJ, ArendtNielsen L 2004 Associations between pain and neuromuscular activity in the human jaw and neck muscles. Pain 109(3):225-232

Tecco S, Tete, S, Festa F 2007 Relation between cervical posture on lateral skull radiographs and electromyographic activity of masticatory muscles in caucasian adult women: a cross-sectional study. Journal of Oral Rehabilitation 34(9):652-662

Vernon H, Mior S 1991 The Neck Disability Index: a study of reliability and validity. Journal of Manipulative and Physiological Therapeutics 14(7):409-415

Waersted M, Hanvold TN, Veiersted KB 2010 Computer work and musculoskeletal disorders of the neck and upper extremity: a systematic review. BMC Musculoskeletal Disorders 11:79-94 